\title{
Effects on Students of Working in Industry
}

\author{
http://dx.doi.org/10.3991/ijac.v8i4.5120 \\ A.S. Blicblau, T.L. Nelson, and K. Dini \\ ${ }^{1}$ Swinburne University of Technology, Hawthorn, Australia
}

\begin{abstract}
This study investigated the impact of two arrangements of work experiences; short term (over 12 weeks, STIE) and long- term (over 52 weeks, LTIE) on both final academic grades and capstone project grades. The results from this work will inform future approaches of determining the benefits to students of the usefulness of industry placed learning experiences (short or long term) as both an indicator of academic performance, and success in capstone project work. Outcomes have shown that engineering graduates without substantial industrial experience often find employment difficult to find in the short time after completing their studies.
\end{abstract}

Index Terms-grades, work integrated learning, industry placed learning, outcomes.

\section{INTRODUCTION}

Immediately after completing their studies engineering graduates without industrial experience may find that employment is difficult to obtain. Anecdotal evidence seems to suggest that work experience or work integrated learning, e.g. short and long term industrial placements (STIE and LTIE) during an engineering course will assist in undertaking capstone projects. Similarly, overall academic results in terms of grade point average (AG), and employment prospects appear to be enhanced by a period spent in industry.

Industry-Based-Learning (commonly referred to as IE in our work) but also denoted as WIL - Work integrated Learning in contemporary work $[1,6,12,13,14,18,20]$ is used for a range of approaches and strategies that integrate academic studies with the work practice. From a series of industry and work related employer interviews, $[1$,$] it was concluded that project work can be utilized to$ provide learning experiences that highlight the relevance of the degree to a particular industry. In a recent UK survey of industry and engineering students on "The Role of Work-integrated learning in Academic Performance", it was found that there was a positive association between industry placements and improved academic performance. However, due to the limited sample size of 60 a somewhat greater sample size was required to validate their claims of correlation [2].

Further evidence has been established that work placement experience brings improved academic performance in addition to the increased skills and employability that can be gained $[3,4]$. The positive effects of industrial placement schemes on academic achievement were noted as one of the major reasons for its implementation [5].

The challenge in the tertiary environment is to determine if the students can translate their work experience to improve their performance academically. Industry based project-based work contains an educational/academic emphasis while exposing the students to workplace environments and interactions. In particular can students im- prove their performance in the capstone project work, and so enhance their employment prospects [6-8].

The purpose of this study was to investigate the impact of two arrangements of work experiences, short term (over 12 weeks, called STIE and long-term or over 52 weeks, termed LTIE) on academic grades (AG), and individually, on capstone grades. The results from this study will guide future approaches in determining the benefits to students of industry-based learning experiences (short or long term) for success in overall academic performance, or attainment of high grades in capstone project work.

\section{INDUSTRY PLACED LEARNING IN AN ACADEMIC CONTEXT}

In an investigation of the link between sandwich placement (a form of LTIE) and academic performance of bioscience students [9], it was found that on average sandwich placement students gain an advantage of nearly $4 \%$ in their overall final year performance over those who did not complete a sandwich program. In the business area, [10] found that there was no significant difference in academic performance on return to studies between students who undertook work placement and those who did not undertake such a placement.

Patrick [1] conducted a large-scale scoping study of work integrated learning in contemporary Australian higher education. His results showed that both universities and participants (students, staff, and industry based supervisors) consistently reported "the positive benefits" of working in industry. Further results provided evidence of commitment and innovative practice about enhancing student learning experiences.

When analyzing the academic results from students who graduated from property management and development courses, Mansfield [11] found that industrial placements were associated with overall higher academic performance in the last year of studies. Similar results from the disciplines of accounting, nursing, and music have all described the benefits of employment in industry during an academic program [12-14]. These benefits included an increase in academic performance in some areas of their studies, an increase in work prospects after graduation, and enhanced attitudes towards their study. In a survey of economics students who had an optional placement year at University of Surrey the [15], it was found that industrial placement "significantly increases the chances of a student obtaining an upper second or higher degree class degree". This positive influence was attributed to either the positive links between maturity and increased reliability and focus by students on both their studies and their work. In another study of the relationship between industrial experience of Business Administration students and their university work, found that students, who complete a placement, perform "better" in "finals." Many other studies have found that students who spend time working in industry 
for either a short or long term period are a benefit for their employment prospects [6, 7, 16-19].

A number of researchers have proposed that although workplace experience may result in undergraduates with improved generic skills which are transferable $[3,4,7,20$, 21] the effect of the work placement upon academic performance is not clear. In a comprehensive study conducted of Australian engineering students [4], researchers found that students had developed strong technical skills in their undergraduate studies, but not necessarily the "soft" skills required for interaction amongst working colleagues.

In many tertiary institutes, 'soft' skills are often scaffolded throughout the engineering program, Often it is not until the work placement experience that the students develop expertise in 'soft' skills. These skills included communication, teamwork, and interpersonal relations and enhanced project management, and implementation skills may provide students with benefits for obtaining employment [3]. In particular, project work, often undertaken during work placement experiences can be utilized to provide learning experiences that highlight the relevance of the degree to a particular industry [1].

At our institution, the undergraduate engineering program promotes student involvement with work-integrated learning (industry-based learning) placement. This program gives undergraduates the opportunity to be placed in either a full year in industry or a six-month placement. This industrial experience usually commences after completion of at least eight semesters of study for a short-term placement (STIE) 12 weeks, or a long-term industry placed learning placement of 52 weeks (LTIE). After completion of their work, the students are expected to return to their university to complete their course.

Students are assessed on the basis of two LTIE reports that are submitted on completion of the placement, as a pass or fail. In any one year, approximately half the local/domestic enrolled students undertake the LTIE program, unless they are not eligible for the LTIE program or choose not to undertake LTIE. International students are not eligible for LTIE. The LTIE program is not compulsory, but the STIE of 12 weeks is a requirement by Engineers Australia as part of the accreditation of the Bachelor of Engineering [22].

\section{PARTICIPANTS}

The current investigation involved a four-year study drawn from a sample of 434 undergraduate mechanical engineering students. The students were completing courses as a single four-year engineering degree and a five-year double degree (combining engineering with business). In their last year of studies, students completed a capstone subject either in the first semester or second semester.

Later in their degree the mechanical engineering students completed either an optional LTIE placement or a 12-week industrial placement; the latter being a professional association requirement for graduation as an engineer [22]. The staff from our office of industry placed learning both located and engaged the majority of students in positions for both LTIE and STIE. These students were placed across a broad spread of industries, ranging from small to large private companies or government and semigovernment organizations.
In some instances, a few engineering students handled negotiating their placements under the guidance of an academic advisor. For those students who had previously undertaken work in industry, an exemption for either STIE or LTIE or both was granted for advanced standing if students have previously completed post-secondary studies (AS) with recognition for prior learning.

The distribution of final year students who had completed (or were exempt from) a work placement program is shown in Figure 1 for LTIE, STIE, and AS. Following their work placement, all the students completed the "capstone" research project in accordance with specific accreditation requirements [22]. Of the capstone enrolled students (over four years), approximately one quarter had completed either LTIE or STIE work placement.

The remainder had worked in industry prior to enrollment in engineering. In about 30 percent of capstone projects, the sponsorship of projects came from the industrial placement companies. In each year, the capstone enrolment cohort in the first semester ranged between 14 and 22 students, whilst in the second semester, the capstone enrolment ranged between 78 and 102, resulting in over 430 students overall. The majority of students complete the capstone project over a full calendar year while a small number commence and complete the project over a financial year. The main reasons are due to either student taking a short six-month "gap" or wanting to continue in a "normal" progression mode over 12 months. A distribution of the student cohort completing the capstone project in either semester 1 or semester 2 is shown in Figure 2.

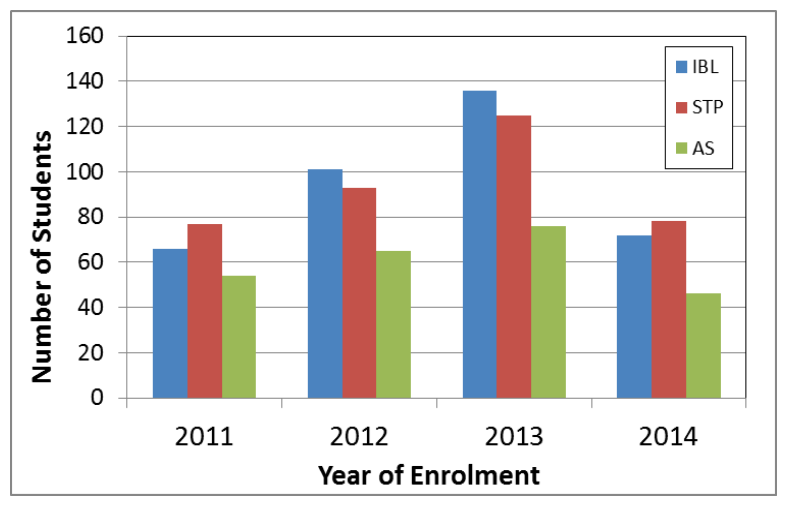

Figure 1. Number final year students (2011-2014) who had completed either a work placement program (short or long) or were exempt due to advanced standing and RPL.

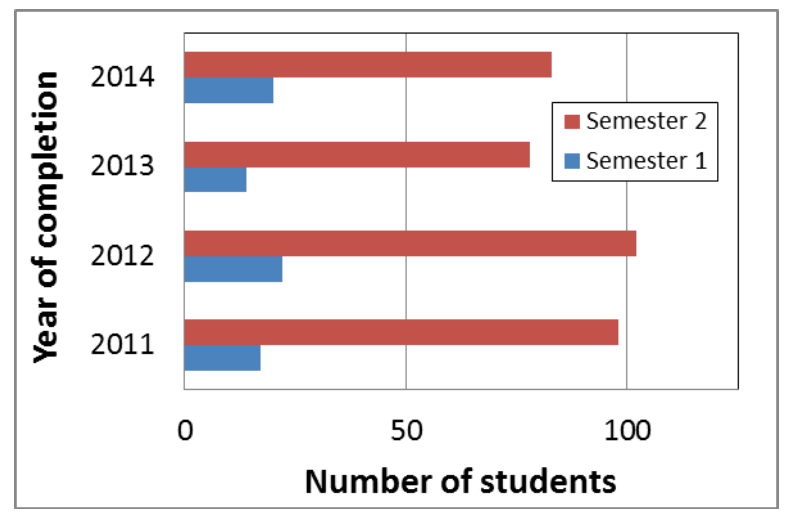

Figure 2. Number of students completing capstone subjects. 
The structure of the engineering degree is such that the majority of students enroll in a four-year academic course, comprising two semesters per year and containing four subjects per semester. The capstone subject is completed in the last semester of the course. In some cases students interrupt their studies (taking a 'gap' period of one or two semesters) and may complete their capstone subject in the "'middle' of the year (this situation is unusual but is consistent from year to year).

\section{DATA COLLECTION}

This process involved the collation of academic grade data from a number of sources: student first year project grades; capstone project grades, and, the final AG. Also, data of the students' involvement in LTIE, STIE or exemption due to previous work experience was collected and correlated against their various academic grades. The data was collected to cover four years (eight semesters). This quantitative data was gathered to determine any predictors of academic performance.

\section{A. Statistical analysis approach}

Ex-post facto quantitative data of student grades was analyzed according to criteria that answered the following queries. The first query explored was "whether the process of LTIE can affect the average grade of mechanical engineering students in subjects taken after completing LTIE." A Paired sample T-test was conducted to evaluate the impact of LTIE on their average grades.

The second query examined the difference between final year (capstone) grades for those students who completed LTIE and those who decided to undertake only a 12 weeks placement in industry (STIE). A one-way analysis of variance between groups was conducted to establish any significant difference between grades of those capstone subjects among students who completed LTIE and those who completed the STIE program. The total data was divided into three groups. The first group was for those who completed LTIE, the second group related to those who completed the STIE program, and a third group is referred to those who did not complete any of those programs. It was noted that some students had not yet completed any of those options and so that data was not incorporated into the analysis.

The third query studied the relation between first-year project subject grades and the final year project (capstone) grades, irrespective of completing time in industry during the course. A Paired sample T-tests was conducted among student grades to compare the grades in the capstone subject and the first-year project subject.

The fourth query was concerned with the impact of students' with prior learning and/or other qualifications on the grades obtained in their final year subject. An Independent sample T-test was conducted among student who either undertook the first-year project subject and those who did not undertake the project subject i.e. AS(RPL) students. These students may have had a TAFE (Teaching and Further Education curriculum) preliminary program called pathway, a trade qualification, or a technical or science qualification) which gave them advanced standing in the engineering degree course.

\section{RESULTS AND DISCUSSIONS}

Statistical analysis of grades concerning capstone and first year project work and industrial placement was performed using the techniques outlined previously. These analyzes involved data mining for overall subject examination grades that provided the data to answer the four queries as discussed below.

For the first query, the analysis outcomes showed that: there was a statistically significant increase in average grades from before LTIE to after LTIE. The increase of the mean was 4.12 with a $95 \%$ confidence interval of the difference ranging from 1.7 to 6.4 .

The statistic indicates that when students completed an LTIE program, the average grades of those subjects that they completed after LTIE was higher than those subjects before completing LTIE. These results indicate that the LTIE program can help students to achieve better marks. A similar phenomenon was found in the UK where the students also achieved a higher form of honors degree [2] after completing a work placement program.

Examining the outcomes of the analysis of the second query, the results showed that there was statistically significant difference at $p<0.05$ in scores for capstone subjects. Post-hoc comparisons, using the Tukey test, indicated that the mean score for the LTIE group was significantly different from the STIE group.

These results indicate that among students sampled in this research, those who completed long-term industry placements achieved better results in their capstone subject when compared with those students who completed 12 weeks in industry. The consequences are that the longer term program (in comparison to the short term program) aided students in attaining higher academic grades in their capstone project.

Further, when analyzing outcomes from the third query, the results indicated that; there was no significant difference between those grades obtained in the first year project subject and for the capstone subject.

These results show that the grade in the first-year project subject had no effect on the grade of the capstone subject, and, in addition, had no impact on students' academic grade achievement overall.

For the fourth and last query, the outcomes of the statistical analysis showed that; there was no significant difference in scores for those who had undertaken the first year project subject and who did not have this subject. The evidence from this last analysis indicates that students' grades for capstone research project have not been affected by a students' qualification prior to attempting the capstone project.

Those students who came into the capstone project with a pre-qualification, on average, achieved capstone grades similar to those who had no pre-qualification. There was an improvement on the quality of the project work compared with those students who had not undertaken a period of long term or short term industry placement. The overall outcomes of the analysis of the four queries indicated the positive benefits of industrial experience on academic performance post-industry placement in the form of the AG, as well as capstone grades. These results for engineering students were similar to results for other professions mentioned previously, [7-8, 12-15]. However, an investigation of a broader range of engineering students, 
disciplines, industries, and educational institutions would be required to provide further demonstration of positive outcomes of working in industry, i.e. better grades overall and in capstone subjects, and enhanced employment prospects. Due to the limited sample size and students selected from only one engineering discipline. A somewhat greater sample size and discipline distribution was required to validate the claims of correlation.

\section{CONCLUSIONS}

There is a positive association between completing an industrial placement (long term and short term ) and achieving a higher capstone project result in the final year of an engineering degree. This evidence may be valuable to both students who are uncertain of the potential benefits of industry placements and tertiary institutes that are deciding whether to incorporate or retain industrial placement programs.

Students' grades for the capstone research project have not been affected by the students' qualification prior to attempting the capstone project. Student grades in the first-year project subject had no effect on the grade of the capstone subject and had no impact on students' achievement overall

For those students who completed the industrial placement, in particular, an LTIE engagement, they achieved better results in their capstone subject when compared with those students who completed an STIE in industry. It is proposed that identifying and optimizing length of work placements are likely to be highly advantageous to students, employers, and higher academic institutions. In a few cases, the work placement experience had resulted in immediate offers of employment with the original employer.

\section{FURTHER WORK}

Future work will involve identifying which specific factors influence academic grades after a period spent working in industry.

\section{ACKNOWLEDGMENTS}

The authors acknowledge the assistance of members of the STEMed (Science, Technology, Engineering, and Mathematics education) research group at SUT.

\section{REFERENCES}

[1] C.-J. Patrick, D. Peach, and C. Pocknee, "The WIL [Work Integrated Learning] report: A national scoping study," Queensland University of Technology, Brisbane, 2009.

[2] Higher Education Task Force, London 2009.

[3] S. A. Male, M. B. Bush, and E. S. Chapman, "Understanding generic engineering competencies", Australasian Journal of Engineering Education, vol. 17, 2011.

[4] S. A. Male, "Generic Engineering Competencies: A Review and Modelling Approach," Education Research \& Perspectives, vol. $37,2010$.

[5] I. T. Wangsa and L. Uden, "Towards the development of industrial placement in Higher Education", in European Models and Best Practice on Practical Placements of Students. Proceedings of the 3rd. EUI-Net International Workshop, Rome, 2007, pp. 9-14.

[6] D. Jackson, "Employability skill development in work-integrated learning: Barriers and best practice," Studies in Higher Education, pp. 1-18, 2013.
[7] D. Jackson, "Modelling graduate skill transfer from university to the workplace", Journal of Education and Work, pp. 1-33, 2014. http://dx.doi.org/10.1080/13639080.2014.907486

[8] R. Mendez and A. Rona, "The Relationship between Industrial Placements and Final Degree Results: a study of engineering placement students," Learning and teaching in higher education, vol. 4, pp. 46-61, 2010.

[9] S. Gomez, D. Lush, and Clements, M., "Work Placements Enhance the Academic Performance of Bioscience Undergraduates", Journal of Vocational Education and Training, vol. 56, pp. 373385, 2004. http://dx.doi.org/10.1080/13636820400200260

[10] J. Duignan, "Undergraduate Work Placement and Academic Performance: failing by doing," presented at the HERDSA Quality Conversations International Conference, Edith Cowan University, Perth, Western Australia, 2002.

[11] R. Mansfield, "The effect of placement experience upon final-year results for surveying degree programmes", Studies in Higher Education, vol. 36, pp. 939-952, 2011. http://dx.doi.org/10.1080/030 75079.2010.486073

[12] I. Abeysekera, "Issues relating to designing a Work-Integrated Learning (WIL) program in an undergraduate accounting degree program and its implications for the curriculum," Faculty of Commerce-Papers, p. 539, 2006.

[13] P. Draper and M. Hitchcock, "Work-integrated learning in music technology: Lessons learned in the creative industries," AsiaPacific Journal of Cooperative Education, vol. 7, pp. 24-31, 2006.

[14] B. Freudenberg, M. Brimble, and C. Cameron, "WIL and generic skill development: The development of business students' generic skills through work-integrated learning," Asia-Pacific Journal of Cooperative Education, vol. 12, pp. 79-93, 2011.

[15] A. Mandilaras, "Industrial Placement and Degree Performance: Evidence for a British Higher Institution,".International Review of Economics Education, vol. 3, pp. 39-51, 2004. http://dx.doi.org/10.1016/S1477-3880(15)30146-8

[16] N. L. Driffield, C. S. Foster, and H. E. Higson, "Placements and degree performance: Do placements lead to better marks, or do better students choose placements?," presented at the ASET Annual Conference, Leeds Metropolitan University, Headingley Campus, 2011.

[17] T. Sahama, A. Oloyede, and P. K. Yarlagadda, "A Learning Oriented Innovation for Graduate Work Preparedness," in Proceedings of the 17th Annual Conference of the Australasian Association for Engineering Education: Creativity, Challenge, Change; Partnerships in Engineering Education, 2006, p. 799.

[18] T. R. Sahama, P. K. Yarlagadda, A. Oloyede, and G. Willet, "Impact of Work Integrated Learning (WIL) on graduate preparation for the manufacturing industry", 2008.

[19] R. K. Coll, K. Zegwaard, and D. Hodges, "Science and technology stakeholders' ranking of graduate competencies Part 1: Employer perspective," Asia-Pacific Journal of Cooperative Education, vol. 3, pp. 19-28, 2002.

[20] B. McLennan and S. Keating, "Work-integrated learning (WIL) in Australian universities: The challenges of mainstreaming WIL," in ALTC NAGCAS National Symposium, 2008.

[21] Engineers Australia. (2013). Program Accreditation. Available: http://www.engineersaustralia.org.au/about-us/programaccreditation.

\section{AUTHORS}

Aaron Blicblau is with SUT Hawthorn Australia 3122, (e-mail: ablicblau@swin.edu.au).

Tracey Nelson is with SUT Hawthorn Australia 3122, (e-mail: tnelson@swin.edu.au).

Kourosh Dini is with SUT Hawthorn Australia 3122, (email:kdini@swin.edu.au).

This article is an extended and modified version of a paper presented at the 2014 IEEE International Conference on Teaching, Assessment and Learning for Engineering (TALE2014), held 8-10 December, Te Papa Tongarewa National Museum of New Zealand, Wellington, New Zealand. Submitted 06 October 2015. Published as resubmitted by the authors 30 November 2015. 